\title{
Decontamination Validation of a Class II Type A2 Biosafety Cabinet during Laboratory Fumigation
}

Applied Biosafety:

Journal of ABSA International 2020, Vol. 25(I) 48-52

(C) ABSA International 2019

Article reuse guidelines:

sagepub.com/journals-permissions DOI: 10.1177/I535676019890975

journals.sagepub.com/home/apb

(S)AGE

\author{
Greg Frey', Cathy Robertson', and Jay Krishnan'
}

\begin{abstract}
Objective: The objective of this study was to evaluate whether a Class II type A2 biosafety cabinet in a laboratory could be decontaminated while the laboratory was being fumigated using vaporous hydrogen peroxide or peracetic acid dry fogging.

Methods: To validate decontamination of all parts of the biosafety cabinet, biological indicators were placed at various locations within the biosafety cabinet, including between the pleats of supply and exhaust HEPA filters. To assess whether the operational status of the biosafety cabinet influenced the outcome of its decontamination, fumigation validations were undertaken with the cabinet running and not running. The amount of fumigant and the duration of fumigation remained constant whether the biosafety cabinet was running or not.

Discussion: Biosafety cabinet decontamination was successful only when the cabinet was running to facilitate the fumigant's circulation within the plenums and across the HEPA filters. This study shows both vaporous hydrogen peroxide and peracetic acid dry fogging can be used successfully to decontaminate Class II type A2 biosafety cabinets during laboratory fumigation, provided the biosafety cabinets are operational and running during the fumigation.
\end{abstract}

\section{Keywords}

fumigation, vaporous hydrogen peroxide, dry fogging system, BSC decontamination, biosafety cabinet

Biosafety cabinets (BSCs) have been widely used in clinical and research laboratories for many years as containment devices to protect the product, environment, and personnel. ${ }^{1,2}$ A BSC, like other laboratory equipment, requires regular maintenance, repair, calibration, and certification. Before internal surfaces or components are accessed or repaired, a BSC needs to be thoroughly decontaminated to prevent personnel exposure, contamination of certification equipment, and release of microbial agents into the surrounding environment. Currently, BSC decontamination is conducted by introducing formaldehyde gas, ${ }^{3,4}$ gaseous chlorine dioxide, ${ }^{5}$ or vaporous hydrogen peroxide (VHP) ${ }^{6}$ directly into individual cabinets. Such an approach is laborious and time consuming, and it requires that the front access opening of individual BSCs be sealed off with plastic sheets and the exhaust filter capped off with custommade hoods to prevent the fumigant from escaping. ${ }^{7}$

A variety of chemical fumigation technologies have been used for the decontamination of high-containment laboratories. Fumigants such as VHP and peracetic acid (PAA) dry fogging are not only efficient but also less harmful to personnel and the environment. Both hydrogen peroxide and PAA are strong oxidants and produce innocuous byproducts such as water and oxygen. ${ }^{8,9}$ Numerous studies have demonstrated the efficacy of VHP and PAA in inactivating microbial agents. VHP has been shown to be effective against bacteria, ${ }^{10}$ bacterial spores, ${ }^{11,12}$ viruses, ${ }^{13}$ and prions. ${ }^{14,15}$ Similarly, PAA has been shown to be an excellent sporicidal, fungicidal, bactericidal, and virucidal disinfectant. ${ }^{16-18}$ Moreover, "the excellent sterilization action of PAA at cold temperatures" was reported as early as $1902,{ }^{19}$ which makes PAA, unlike other disinfectants, an ideal disinfectant for sterilization-in-place by the food processing industry. ${ }^{9}$

In addition to being used for laboratory decontamination, VHP has been used to decontaminate hospital rooms, ambulances, clean rooms, animal rooms, large volume filling rooms, and Ebola treatment units. ${ }^{10,20-25}$ Dry fog with PAA has been used to decontaminate high-containment laboratories, decontamination chambers, and cell culture facilities. ${ }^{17,26,27}$ In this study, we wanted to validate whether VHP and PAA dry fogging system could be used to decontaminate BSCs in situ during a laboratory fumigation process.

\footnotetext{
' National Microbiology Laboratory, Public Health Agency of Canada, Winnipeg, MB, Canada

Corresponding Author:

Jay Krishnan, Safety \& Environmental Services, National Microbiology Laboratory, Public Health Agency of Canada, 1015 Arlington Street, Winnipeg, MB, Canada R3E 3P6.

Email: jay.krishnan@canada.ca
} 
Table I. Location of Biological Indicators (BI) Placed within the Biosafety Cabinet (BSC) for Decontamination during Laboratory Fumigation.

\begin{tabular}{|c|c|c|c|}
\hline \multirow{2}{*}{$\begin{array}{l}\text { Serial } \\
\text { No. }\end{array}$} & \multirow[b]{2}{*}{ Location } & \multicolumn{2}{|c|}{ BI Results } \\
\hline & & BSC on & BSC off \\
\hline 01 & Top of exhaust HEPA, right side, back corner & Pass & Pass \\
\hline 02 & $\begin{array}{l}\text { Negative plenum, left wall, beside exhaust } \\
\text { filter box }\end{array}$ & Pass & Pass \\
\hline 03 & $\begin{array}{l}\text { Upper negative plenum back wall, right side } \\
\text { middle }\end{array}$ & Pass & Pass \\
\hline 04 & $\begin{array}{l}\text { Upper negative plenum, front on blower } \\
\text { housing }\end{array}$ & Pass & Pass \\
\hline $05^{\mathrm{a}}$ & $\begin{array}{l}\text { Common plenum, back left-hand side of } \\
\text { supply HEPA }\end{array}$ & Pass & Fail \\
\hline $06^{\mathrm{a}}$ & Common plenum, right side wall & Pass & Fail \\
\hline $07^{\mathrm{a}}$ & $\begin{array}{l}\text { Common plenum, front middle on supply } \\
\text { HEPA frame }\end{array}$ & Pass & Fail \\
\hline $08^{\mathrm{a}}$ & $\begin{array}{l}\text { On the cover plate (middle) common } \\
\text { plenum }\end{array}$ & Pass & Fail \\
\hline 09 & Middle of supply diffuser in work area & Pass & Pass \\
\hline 10 & Middle of back wall in work area & Pass & Pass \\
\hline II & Below work tray, left side & Pass & Pass \\
\hline 12 & Below work tray, right side & Pass & Pass \\
\hline $13^{\mathrm{a}}$ & $\begin{array}{l}\text { Left side, in the pleats of supply HEPA (dirty } \\
\text { side) }\end{array}$ & Pass & Fail \\
\hline $14^{\mathrm{a}}$ & Exhaust HEPA, in the pleats (clean side) & Pass & Fail \\
\hline $15^{\mathrm{a}}$ & $\begin{array}{l}\text { Right side, in the pleats of supply HEPA } \\
\text { (clean side) }\end{array}$ & Pass & Fail \\
\hline
\end{tabular}

${ }^{a}$ These Bls failed consistently across all 3 replicate runs.

\section{Materials and Methods}

BSC decontamination validations were done in a decontamination room, which was built using metal stud framing and 1/4inch-thick polypropylene walls. The sealable room was built to replicate the size of a small laboratory (16 feet wide, 8 feet deep, and 8 feet high) with 10 air changes per hour. This room has been regularly used for fumigating large pieces of laboratory equipment coming out of high-containment laboratories for repair or surplus using repeatedly validated and wellestablished VHP or PAA dry fog cycles. For this study, a 4-foot Class II type A2 BSC (SG400; Baker Company, Sanford, $\mathrm{ME}$ ) was placed toward one end of the room for the validations using the established decontamination cycles. Just before a fumigation cycle was started, the air system was manually shut down and the gaps around the door were sealed with duct tape to prevent fumigant leakage, as described previously. ${ }^{26}$

15 commercially available Geobacillus stearothermophilus biological indicators (BIs) (Steris Corporation, Mentor, $\mathrm{OH}$ ) were placed at various locations within the BSC (Table 1). Because this room has been previously validated repeatedly for VHP and PAA fumigation, no additional BIs were placed in the room. After exposure and aeration of the room and the BSC, all of the BIs were retrieved, transferred to tubes of trypticase soy broth containing phenol red, and incubated at $56^{\circ} \mathrm{C}$ for up to 7 days. Development of a yellow color and turbidity in any of the $15 \mathrm{BIs}$ indicated bacterial growth (ie, decontamination failure), whereas no change in turbidity and the original pink color of the media inferred inactivation of BIs (ie, decontamination successful).

\section{Fumigation Using Vaporous Hydrogen Peroxide}

A VHP generator (VHP1000ARD; Steris Corporation, Mentor, $\mathrm{OH})$ was used for the fumigation. The sterilant used in the generator was $35 \% \mathrm{H}_{2} \mathrm{O}_{2}$ (Vaprox; Steris Corporation, Mentor, $\mathrm{OH})$. VHP was introduced into the room via a $1-1 / 2-$ inch camlock port on the front wall; a second $1-1 / 2$-inch port was used to return the vapor to the VHP generator (Figure 1). The previously established room decontamination program cycle that was used for the validation runs $(\mathrm{n}=3)$ included dehumidification to $13.8 \mathrm{mg} / \mathrm{L}$ absolute humidity (30 minutes), conditioning sterilant injection of $7.0 \mathrm{~g} / \mathrm{min}$ for 10 minutes, decontamination sterilant injection of $5.3 \mathrm{~g} / \mathrm{min}$ for 45 minutes, and a delay of 12 hours before the room's aeration phase.

\section{Fumigation Using PAA Dry Fogg}

An in-house assembled dry fogger (Figure 2) was used for this validation study. The dry fogger head and nozzle were purchased from Ikeuchi USA (Blue Ash, $\mathrm{OH}$ ) and were fitted on the lid of a 1-gallon Nalgene bottle (ThermoFisher Scientific, Waltham, MA). An air compressor (model 2807CE72; Thomas, Monroe, LA) that was able to deliver a maximum of 50 psi continuous pressure was used; however, only 30 psi was sufficient for operating 1 nozzle for the small room (larger rooms would require more than 1 nozzle). The compressor was plugged into a wall power socket via a receiver that could be turned on or off using a remote switch from outside the room. The amount of PAA required for the room fumigation was calculated as described elsewhere. ${ }^{26}$ Briefly, it was calculated using variables such as relative humidity, temperature, and volume of the room being fumigated. For this room, the typical amount of PAA required was less than $700 \mathrm{~mL}$ of $1 / 10$ diluted Minncare Cold Sterilant, a commercially available liquid PAA from Mar Cor Purification (Skippack, PA). Minncare contains 4.5\% PAA and 22\% $\mathrm{H}_{2} \mathrm{O}_{2}$. For all 3 replicate validation runs, the Nalgene bottle was filled with $700 \mathrm{~mL}$ of freshly diluted Minncare, and any leftover amount was properly discarded after the fumigation. The fogging was allowed to run until the relative humidity in the decontamination room had risen to approximately $85 \%$, which took 13 to 15 minutes. The fogger was then turned off by cutting the power to the air compressor and was left undisturbed overnight.

\section{Results}

All of the BIs were inactivated for all 3 replicate runs when the $\mathrm{BSC}$ was left running during the room fumigation using either VHP or the dry fog. However, the decontamination attempts using VHP and dry fog with the BSC shut off failed to inactivate all of the BIs, especially the ones placed in the HEPA filter pleats and internal plenums (Table 1). It was evident that the BSC had to be operational and running for it to take up the 


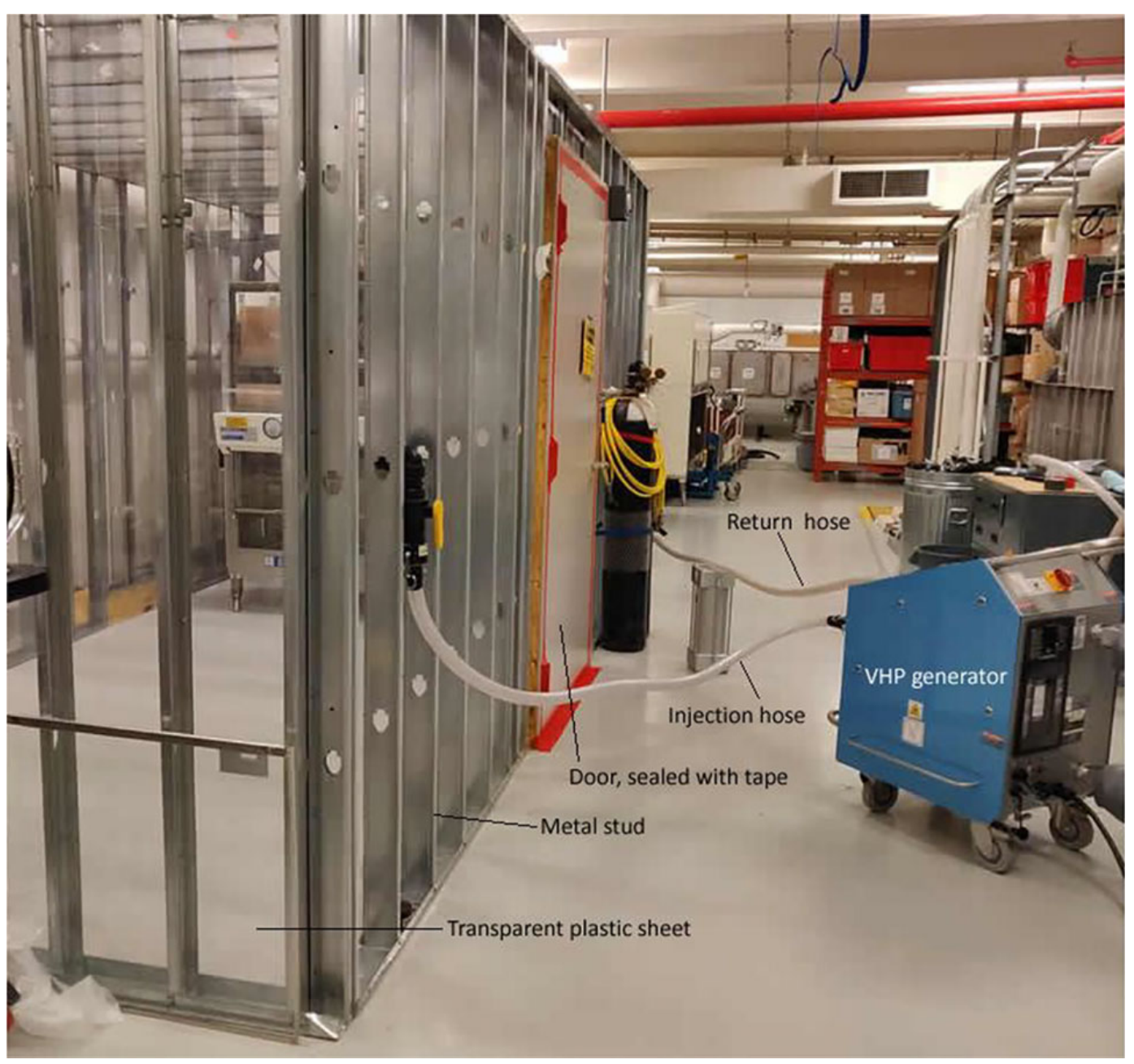

Figure I. Vaporous hydrogen peroxide (VHP) fumigation setup. Decontamination room with the biosafety cabinet inside is connected to the VHP generator and ready for fumigation.

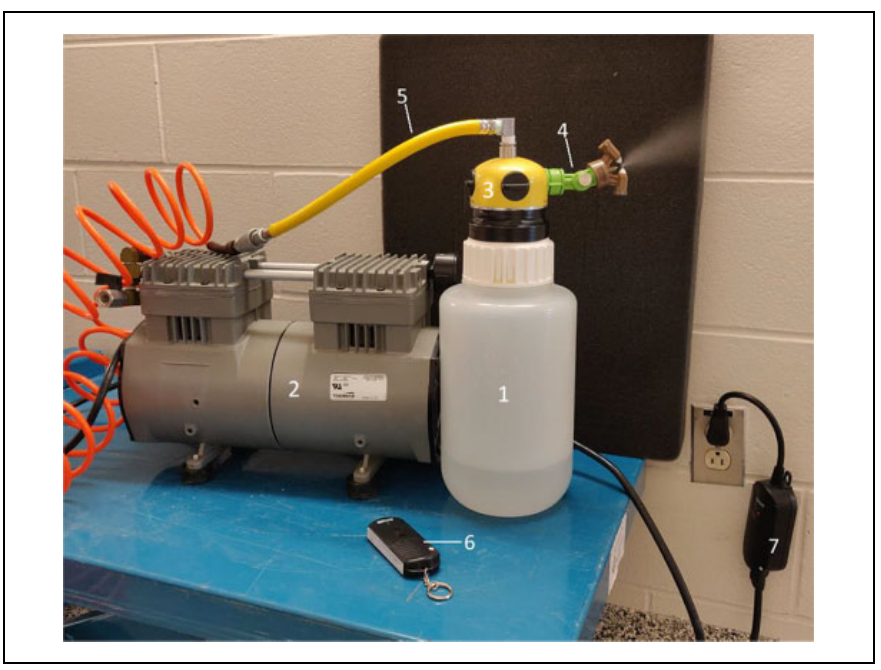

Figure 2. Dry fogging system used for decontaminating the laboratory room and the biosafety cabinet. (I) One-gallon Nalgene bottle. (2) Air compressor. (3) Fog head with 3 nozzles capped. (4) Fog nozzle. (5) Hose connecting the air compressor to fog head. (6) Remote power control switch. (7) Remote power control receiver.

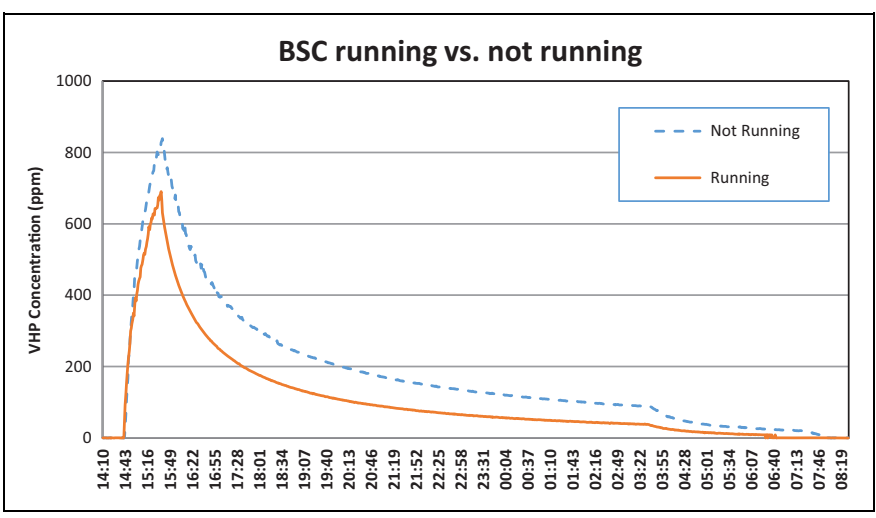

Figure 3. Vaporous hydrogen peroxide (VHP) concentration profile recorded in the room while the biosafety cabinet (BSC) was running vs not running. VHP concentration in the room was monitored using a Dräger Ploytron 2 transmitter fitted with a highconcentration hydrogen peroxide sensor. The data were captured using an Omega OM-CP-Process II 0 data logger connected to the transmitter. 
fumigant from the room to be distributed across the HEPA filters and the plenums for effective decontamination.

We also compared differences in the volume of PAA consumed when the BSC was running versus not running; more than $10 \%$ volume was required when the BSC was running (data not shown). Similarly, a higher concentration of VHP (839 ppm) was recorded in the room when the BSC was not running as opposed to a lower concentration (691 ppm) when the BSC was running (Figure 3).

\section{Discussion and Conclusion}

Several studies have shown how to successfully decontaminate a BSC using various fumigation technologies; however, their approach had entailed decontaminating $1 \mathrm{BSC}$ at a time by directly introducing the fumigant into the cabinet, which is a laborious and time-consuming process. A recent study ${ }^{28}$ showed the successful decontamination of a BSC using plasma-activated aerosolized hydrogen peroxide during laboratory fumigation. Here, we investigated whether the same could be accomplished using VHP and PAA dry fog. In this study, we used a VHP and PAA dry fogging system to successfully decontaminate a Class II A2 BSC during laboratory fumigations. The VHP was generated with a Steris VHP generator and the dry fog with a Ikeuchi dry fogger head and nozzle. In these series of validations, we showed both the VHP and the PAA dry fog are capable of decontaminating a Class II A2 BSC successfully, as long as the cabinet is operational and running. The initial validations conducted with the BSC turned off failed to inactivate all the BIs placed in the BSC, indicating a failure of the BSC decontamination, even when the decontamination room was filled with the fumigant overnight. This means that a BSC that has a nonworking motor or is otherwise nonoperational cannot be decontaminated during laboratory fumigation. Such a BSC will have to be decontaminated individually by sealing off the front access opening and the exhaust filter, as described in a previous study. ${ }^{7}$

The BSC used a noticeable amount of fumigant while running; more than $10 \%$ volume of PAA was required to achieve the same levels of relative humidity in the room; similarly, a lower VHP concentration (peaked at $691 \mathrm{ppm}$ ) was observed when the BSC was running as opposed to when the BSC was not running (peaked at $839 \mathrm{ppm}$ ). This was not a surprising finding; more fumigant would be required to fill the internal plenums of a BSC while it is running. Moreover, HEPA filter media would also soak up noticeable amounts of fumigant, as reported previously, ${ }^{29}$ which would also contribute to a lower concentration in the room. How such reduced levels of fumigant concentration would affect the overall laboratory fumigation processes requires further consideration, especially if one is intending to fumigate a laboratory with multiple BSCs using a shorter contact time. Fumigation contact time is not a limiting factor for us, as it has always been the practice in our facility to allow at least 12 hours or overnight contact time to ensure thorough decontamination of the laboratory.

High-containment laboratories, especially BSL-4 laboratories, require yearly fumigation and shut-down for preventive maintenance, annual performance verification, and recertification. It would increase efficiency and decrease laboratory down time if all of the BSCs in the laboratory could be decontaminated during the laboratory fumigation process. However, such an approach cannot be adopted without thorough and repeated validations. Various national and international standards and guidelines such as the Canadian Biosafety Standard, ${ }^{30}$ Biosafety in Microbiological and Biomedical Laboratories, ${ }^{31}$ and Select Agents and Toxins Biosafety/Biocontainment Plan Guidance $^{32}$ require laboratories to establish or adopt validated decontamination processes for safe laboratory operations.

Formaldehyde gas and chlorine dioxide gas are the other two popular choices for BSC decontamination; they also require validation to verify whether $\mathrm{BSC}$ decontamination can be accomplished during laboratory fumigation. Although formaldehyde is less expensive than aerosolized hydrogen peroxide, VHP, and chlorine dioxide gas technologies, it is a known human carcinogen. ${ }^{33}$ A PAA dry fogging system is an efficient and reliable fumigation technology and, like formaldehyde, is relatively inexpensive. Formaldehyde fumigation, however, requires neutralization and cleanup; the latter would require several hours of labor, adding to the overall downtime and cost. In comparison, PAA dry fog, chlorine dioxide gas, and VHP require no postprocess neutralization or cleanup.

HEPA filters function by arresting particles; since dry fogging creates small particles of $7.5 \mu \mathrm{m}$ in average size, we and others $^{28}$ have hypothesized that the PAA fog particles would be stopped by the BSC's HEPA filters, thus making the fog unavailable to decontaminate parts of the BSC past the filters. Our data suggest that the chemical (PAA) was able to traverse across the filters even when the PAA fog particles were arrested by the filter media. Both VHP and PAA dry fogging systems are environmentally friendly (oxygen and water byproducts) and compatible with laboratory equipment and electronics. $^{26}$

In conclusion, this study shows both the VHP and the PAA dry fogging systems are capable of decontaminating a Class II A2 BSC successfully during laboratory fumigations, so long as the cabinet is operational and running.

\section{Ethical Approval Statement}

Authors declare no work was performed on human subjects or laboratory animals during the course of the study and was not subjected to a formal approval by a relevant ethics committee or institutional review board.

\section{Statement of Human and Animal Rights}

No human subjects or animals were used.

\section{Statement of Informed Consent}

No written or oral informed consent statements were required for this study.

\section{Declaration of Conflicting Interests}

The authors declared no potential conflicts of interest with respect to the research, authorship, and/or publication of this article. 


\section{Funding}

The authors disclosed the following financial support for the research, authorship, and/or publication of this article: This work was supported by funds from the Public Health Agency of Canada, Government of Canada.

\section{References}

1. Coriell LL, McGarrity GJ. Biohazard hood to prevent infection during microbiological procedures. Appl Microbiol. 1968;16(12): 1895-1900.

2. McDade JJ, Sabel FL, Akers RL, Walker RJ. Microbiological studies on the performance of a laminar airflow biological cabinet. Appl Microbiol. 1968;16(7):1086-1092.

3. Fink R, Liberman DF, Murphy K, Lupo D, Israeli E. Biological safety cabinets, decontamination or sterilization with paraformaldehyde. Am Ind Hyg Assoc J. 1988;49(6):277-279.

4. Luftman H. Neutralization of formaldehyde gas by ammonium bicarbonate and ammonium carbonate. Appl Biosaf. 2005;10(2):101-106.

5. Luftman HS, Regits MA, Lorcheim P, Lorcheim K, Paznek D. Validation study for the use of chlorine dioxide gas as a decontaminant for biological safety cabinets. Appl Biosaf. 2008;13(4):14.

6. Hillman D. Vapor phase hydrogen peroxide gas decontamination of a BSC. Perform Rev. 2004;10(3):10-11.

7. Fey G, Klassen S, Theriault S, Krishnan J. Decontamination of a worst-case scenario Class II biosafety cabinet using vaporous hydrogen peroxide. Appl Biosaf. 2010;15(3):142-150.

8. Rickloff JR, Graham GS. Vapor phase hydrogen peroxide sterilization. J Healthc Mater Manage. 1989;7(5):45-46, 48.

9. Orth R. The importance of disinfection for the hygiene in the dairy and beverage production. Int Biodeter Biodegr. 1998; 41(3):201-208.

10. French GL, Otter JA, Shannon KP, Adams NM, Watling D, Parks MJ. Tackling contamination of the hospital environment by methicillin-resistant Staphylococcus aureus (MRSA): a comparison between conventional terminal cleaning and hydrogen peroxide vapour decontamination. J Hosp Infect. 2004;57(1):31-37.

11. Ali S, Muzslay M, Bruce M, Jeanes A, Moore G, Wilson AP. Efficacy of two hydrogen peroxide vapour aerial decontamination systems for enhanced disinfection of methicillin-resistant Staphylococcus aureus, Klebsiella pneumoniae and Clostridium difficile in single isolation rooms. J Hosp Infect. 2016;93(1):70-77.

12. Wood JP, Calfee MW, Clayton M, et al. A simple decontamination approach using hydrogen peroxide vapour for Bacillus anthracis spore inactivation. J Appl Microbiol. 2016;121(6):1603-1615.

13. Pottage T, Richardson C, Parks S, Walker JT, Bennett AM. Evaluation of hydrogen peroxide gaseous disinfection systems to decontaminate viruses. $J$ Hosp Infect. 2010;74(1):55-61.

14. Fichet G, Comoy E, Duval C, et al. Novel methods for disinfection of prion-contaminated medical devices. Lancet. 2004; 364(9433):521-526.

15. Rogez-Kreuz C, Yousfi R, Soufflet C, et al. Inactivation of animal and human prions by hydrogen peroxide gas plasma sterilization. Infect Control Hosp Epidemiol. 2009;30(8):769-777.

16. Hussaini SN, Ruby KR. Sporicidal activity of peracetic acid against B anthracis spores. Vet Rec. 1976;98(13):257-259.
17. Gregersen JP, Roth B. Inactivation of stable viruses in cell culture facilities by peracetic acid fogging. Biologicals. 2012;40(4): 282-287.

18. Greenspan FP, MacKellar DG. The application of peracetic acid germicidal washes to mold control of tomatoes. Food Technol. 1951;5(3):95-97.

19. Freer PC, Novy FG. On the formation, decomposition, and germicidal action of benzoylacetyl and diacetyl peroxides. Am Chem J. 1902;27:161-193.

20. Krishnan J, Berry J, Fey G, Wagener S. Vaporized hydrogen peroxide-based biodecontamination of a high-containment laboratory under negative pressure. Appl Biosaf. 2006;11(2):74-80.

21. Jahnke M, Gerhard L. Biodecontamination of a large volume filling room with hydrogen peroxide. Pharm Eng. 1997;17(4): 96-108.

22. US Department of Homeland Security. Portable Ambulance Decontamination Systems Market Survey Report. Washington, DC: US Department of Homeland Security; 2015.

23. Krause J, McDonnell G, Riedesel H. Biodecontamination of animal rooms and heat-sensitive equipment with vaporized hydrogen peroxide. Contemp Top Lab Anim Sci. 2001;40(6):18-21.

24. Meszaros JE, Antloga K, Justi C, Plesnicher C, McDonnell G. Area fumigation with hydrogen peroxide vapor. Appl Biosaf. 2005;10(2):91-100.

25. Otter JA, Mepham S, Athan B, et al. Terminal decontamination of the Royal Free London's high-level isolation unit after a case of Ebola virus disease using hydrogen peroxide vapor. Am J Infect Control. 2016;44(2):233-235.

26. Krishnan J, Fey G, Stansfield C, et al. Evaluation of a dry fogging system for laboratory decontamination. Appl Biosaf. 2012;17(3): 132-141.

27. Wood JP, Calfee MW, Clayton M, Griffin-Gatchalian N, Touati A, Egler K. Evaluation of peracetic acid fog for the inactivation of Bacillus anthracis spore surrogates in a large decontamination chamber. J Hazard Mater. 2013;250-251:61-67.

28. Freyssenet C, Karlen S. Plasma-activated aerosolized hydrogen peroxide (aHP) in surface inactivation procedures. Appl Biosaf. 2019;24(1):10-19.

29. Stansfield C, Anderson K, Fey G, Krishnan J, Robertson C. BSL4 decontamination: VHP through the filter or not? Poster presented at: 53nd American Biological Safety Association Conference; October 4, 2010; Denver, CO.

30. Canadian Biosafety Standard, 2nd ed. https://www.canada.ca/con tent/dam/phac-aspc/migration/cbsg-nldcb/cbs-ncb/assets/pdf/ cbsg-nldcb-eng.pdf. Accessed November 1, 2019.

31. Biosafety in Microbiological and Biomedical Laboratories. https://www.cdc.gov/labs/pdf/CDC-BiosafetyMicrobiological BiomedicalLaboratories-2009-P.PDF. Accessed November 1, 2019.

32. Select Agents and Toxins Biosafety/Biocontainment Plan Guidance. https://www.selectagents.gov/resources/Biosafety_Gui dance.pdf. Accessed November 1, 2019.

33. International Agency for Research on Cancer. FormaldehydeIARC Monographs. 2018. https://monographs.iarc.fr/wp-con tent/uploads/2018/06/mono100F-29.pdf. Accessed November 1, 2019. 